\title{
THE KENTRIODONTIDAE AND THE ORIGIN OF THE DELPHINOIDS
}

DAWSON*, Susan D., Department of Anatomy, College of Veterinary Medicine, Cornell University, Ithaca, NY, 14853, U.S.A.; BOHASKA, David J., Department of Paleobiology, National Museum of Natural History, Smithsonian Institution, Washington, DC, 20560, U.S.A.; FORDYCE, R. Ewan, and ICHISHIMA, Hiroto, Department of Geology, University of Otago, PO Box 56, Dunedin, New Zealand.

Modern Delphinoidea (Monodontidae, Phocoenidae and Delphinidae) represent the most diverse radiation among extant cetaceans. The odontocete family Kentriodontidae has long been considered basal to the delphinoid radiation, although basic systematic issues of this group remain poorly understood. The Kentriodontidae have not been shown to be monophyletic, and should be considered a grade-level assemblage. Precise relationships with modern delphinoids are not resolved, nor are their relationships to more primitive odontocetes. Kentriodontids, however, are not related to the Platanistoidea. At least thirteen genera in four subfamilies have been described as kentriodontids, with Kentriodon appearing to be particularly speciose. These taxa represent considerable geographic, temporal and morphologic diversity. Kentriodontids had world-wide distribution, with specimens recovered from Europe, North America, South America, Japan, and New Zealand. This worldwide distribution was achieved by at least Early Miocene; although poorly known, kentriodontids have also been reported from the Late Oligocene. Kentriodontids are not known later than Late Miocene.

Although several taxa are known only from incomplete and poorly preserved skulls, at least eight genera are known from specimens which consist of skulls and postcranial material. These relatively complete specimens allow for comparison of the kentriodontid functional and ecological morphology. Morphological diversity suggests not only a transition from primitive to advanced odontocetes, but also a range of ecological specializations. Number of teeth, rostral length, vertebral morphology, and forelimb morphology may be correlated with principal prey preference, habitat, and locomotor characters such as swimming speed and maneuverability. 